\title{
Haines, S. and Ruebain, D. (Eds.) (first published 2011). Education, disability and social policy. Bristol: Policy Press. 208 p., ISBN-13: 978-1847423375.
}

Reviewed by NiKa ŠUšTERIČ

"The authors (...) consider the advances, challenges and difficulties that make up current experience of disabled students and look to the future of what might come next in the pursuit of greater educational opportunities."

Steve Haines and David Ruebain Education, disability and social policy 2011, p. 1

The question of educating children with disabilities and special needs is becoming more and more discussed, both in the field of education and among various stakeholders in society. With this in mind, we cannot be surprised at the growing number of books, articles and journals dedicated to debating this issue from various standpoints. The book Education, disability and social policy, edited by Steve Haines and David Ruebain, contributes its share to this diverse corpus of works. In the words of the editors, the book "considers the progress that has been made since the 1980 os in educational provision in the UK for disabled students (...)" (Haines \& Ruebain, 2011, p. 1). Despite the fact that it mostly considers UK policy and legislation regarding the education of children with disabilities, this publication may also be of interest to students, researchers, theorists, practitioners and other interested individuals from other countries, as it offers a view on some topics relevant to education, as well as cautions about some possible (unwanted) consequences that can be produced by various policies.

Education, disability and social policy includes contributions by authors from various backgrounds - theorists, practitioners, activists - enabling a discussion rooted in the perspectives of various levels and fields of engagement in the education of children with disabilities, thus giving the book a specific value. While it seems that, at least implicitly, the common denominator of all of the authors is a tendency towards the meaningful and efficient realisation of inclusion, they debate different topics related to education in general and to that of children with disabilities in particular. They do so mostly through the prism of existing policy and legislation regarding children with disabilities from the Warnock report on, focusing primarily on the effects of the most recent policy and legislation (such as The Children's Plan: Building Brighter Futures (2007), The 
Lamb Inquiry: Special Education Needs and Parental Confidence (2009), Support and Aspiration: A New Approach to Special Educational Needs and Disability: A Consultation (2011), Removing Barriers to Achievement: The Government's Strategy for SEN (2004), Disability Discrimination Act (1995), Aiming High for Disabled Children (2007), Every Disabled Child Matters (2009), Equality Act (2010), The Special Educational Needs and Disability Act 2001, and others), with an eye on the outcomes they bring for inclusive education.

Thus the first article in the book, entitled Disability and education in historical perspective by A. Borsay, briefly presents the history of schooling of children with disabilities in Britain, with a particular focus on the inability of legal entitlements to enforce inclusive schooling, on the contribution of professions to this failure, and on the impact on human rights brought about by the weakened participation of children with disabilities in their families, communities and employment due to segregated schooling. The role of professions and multi-agency working in educating children with disabilities is further elaborated in the article by L. Todd, Multi-agency working and disabled children and young people: from 'what works' to 'active becoming'. The article by C. Booth, M. Bush and R. Scott offers an insight into policy and legislation concerning children with disabilities that have mostly developed in the fields of education, care and disability discrimination. The authors vividly illustrate the undesired effects caused by the interplay of legislation and policy and by the gap between formal regulation and actual practice.

P. Russell touches upon the subject of the family and its role in the education of children with disabilities. She outlines the policies that empower the role of parents, positioning them as central to achieving the objectives regarding children with disabilities. The article also briefly discusses the growing importance of the child's 'voice' in determining the course of their own education. A. Lewis presents a more detailed explanation of the importance and possible implications of hearing children's 'voices'. In her article Disabled children's 'voice' and experience she also highlights some guidelines on the methods, the research ethics, in exploring children's standpoints, as well as the possible outcomes of acknowledging them.

One of the most important issues in education in general is debated by O. Miller, R. Cobb and P. Simpson. Their article discusses the assessment and attainment of children with disabilities, especially those conditioned by hearing, visual and multi-sensory impairments. They explore the implications of a system that aims at assuring universal services for all children and young people, on the one hand, and on setting and streaming based on the outcomes of national tests and formal examinations, on the other. There is no denying 
that assessment and attainment are crucial for enrolment in further levels of education. The question of higher education and people with disabilities - its development, challenges and unresolved questions - is discussed by S. Riddell and E. Weedon in their paper Access to higher education for disabled students: a policy success story? One concept that might have the capacity to reconcile and solve these seemingly opposite tendencies and remaining tasks is presented by N. Crowther in his article From SEN to Sen: could the 'capabilities approach' transform the educational opportunities of disabled children? Cowther claims the death of inclusion by presenting the 'capabilities approach', founded in the theory of Amartya Sen, which is, according to Crowther, underpinned by the same human rights principles as inclusion. The concept focuses on capabilities as those enabling people to achieve 'functionings' (amongst which Crowther lists staying safe, acquiring knowledge and others). It is these capabilities that schools should provide all children with. Considering the education of disabled and other children from this standpoint might be in concurrence with human rights, and could meet the Every Child Matters objectives of being healthy and safe, enjoying and achieving through learning, making a positive contribution to society, and achieving economic wellbeing.

All in all, by covering various topics, the book succeeds in illustrating the complexity of the field of the education of children with disabilities. It provides the reader with a general view of the existing policy and legislation, taking into account recent developments in this field. The latter provide a basis for considering possible future developments in education in the light of the current crisis and related public expenditure cuts. Such cuts will leave their mark on education in general, and are very likely to harm the most disadvantaged groups more than others. Bearing all of this in mind, the book acknowledges the intertwinement of education and other parts of society. Taking account of the effects of policy and legislation, it provides the foundations for considering education as inevitably embedded in broader social structures.

However, a reader searching for conceptualisations of disability in general, and for the consequences of these conceptualisations for policymaking and education, might be unsatisfied. The editors have shaped the book claiming that their "own starting point is to consider these issues through the perspective of the social model of disability" (ibid., p. 1). To clearly position oneself is fair, acceptable and very probably inevitable. Yet the reader might find himself or herself unable to get rid of the feeling that presupposing the social model of disability actually turns out to be a presumption of inclusive education, the latter being the "right way" of educating all children. While inclusive education can be derived as a possible form of education that can suffice the demands of 
(a certain reading of) the social model of disability, it is not a logically necessary consequence of acknowledging this model. An article discussing the relationship between inclusive education and the social model of disability, or, in other words, discussing possible alternatives to education derived from the social disability model, would thus be welcome.

In conclusion, despite some reservations, the book, especially due to the broad considerations of social policy, satisfies its goal to "stimulate debate and provide considerable food for thought about current issues, recent developments and possible solutions" (ibid., p. 5). Although a wider conceptual framework is necessary for a comprehensive consideration of the education of children with disabilities and related social policy, the lack of this framework cannot reduce the value of the present book. 